\title{
Exposure to traffic noise and gestational weight gain and postpartum weight retention: a cohort study
}

\author{
Mette Sørensen (1) 1,2 Thorkild I A Sørensen, 3,4 Matthias Ketzel, ${ }^{5,6}$ \\ Ole Raaschou-Nielsen ${ }^{1,5}$
}

- Additional material is published online only. To view please visit the journal online (http://dx.doi.org/10.1136/ oemed-2019-105843).

'Diet, Genes and Environment, Danish Cancer Society Research Center, Copenhagen, Denmark ${ }^{2}$ Department of Natural Science and Environment, Roskilde University, Roskilde, Denmark ${ }^{3}$ Novo Nordisk Foundation Center for Basic Metabolic Research, Faculty of Health and Medical Sciences, University of Copenhagen, Copenhagen, Denmark

${ }^{4}$ Department of Public Health, Section of Epidemiology, Faculty of Health and Medical Sciences, University of Copenhagen, Copenhagen, Denmark ${ }^{5}$ Department of Environmental Science, Aarhus University, Roskilde, Denmark

${ }^{6} \mathrm{Global}$ Centre for Clean Air Research (GCARE), University of Surrey, Guildford, UK

Correspondence to Dr Mette Sørensen, Danish Cancer Society, Copenhagen 2100, Denmark;

mettes@cancer.dk

Received 28 March 2019 Revised 18 August 2019 Accepted 18 November 2019

\section{ABSTRACT}

Objectives Transportation noise has been associated with markers of obesity. We aimed to investigate whether road traffic and railway noise were associated with weight gain during and after pregnancy.

Methods Among the women participating in the Danish National Birth Cohort, 74065 reported on weight before and during the pregnancy (gestational week 30) and 52661 reported on weight before and 18 months after pregnancy. Residential address history from conception to 18 months after pregnancy was obtained in national registers, and road traffic and railway noise were modelled for all addresses. Associations between noise and gestational weight gain (GWG) and postpartum weight retention (PPWR) were analysed using the linear and log-binomial regression.

Results $A 10 \mathrm{~dB}(\mathrm{~A})$ higher road traffic noise was associated with an increase in GWG of $3.8 \mathrm{~g} /$ week $(95 \%$ $\mathrm{Cl} 2.3$ to 5.3) and PPWR of $0.09 \mathrm{~kg}(95 \% \mathrm{Cl} 0.02$ to $0.16)$. For PPWR, this association seemed confined to women who were overweight $(0.17 \mathrm{~kg}, 95 \% \mathrm{Cl} 0.02$ to 0.32 ) or obese $(0.49 \mathrm{~kg}, 95 \% \mathrm{Cl} 0.26$ to 0.73$)$ before pregnancy. Further adjustment by nitrogen dioxide reduced GWG risk estimates and slightly increased PPWR risk estimates. Railway noise $\geq 65 \mathrm{~dB}(\mathrm{~A})$ was associated with an increase in GWG of $4.5 \mathrm{~g} /$ week $(95 \% \mathrm{Cl}-2.7$ to 11.6) and PPWR of $0.26 \mathrm{~kg}(95 \% \mathrm{Cl}-0.09$ to 0.60$)$ compared with levels $<55 \mathrm{~dB}(\mathrm{~A})$.

Conclusions Our findings suggest that road traffic noise is associated with weight gain during and after the pregnancy, which adds to the literature linking transportation noise to adiposity.

\section{INTRODUCTION}

Transportation noise is classified as the second worst environmental risk factor. ${ }^{1}$ It has been associated with a wide range of diseases and conditions, including adiposity and diabetes. ${ }^{2-6}$ The dominating source is road traffic and although WHO recommends to reduce road traffic noise below $53 \mathrm{~dB}(\mathrm{~A})$ to prevent adverse health effects, ${ }^{7}$ it is estimated that at least $24 \%$ of the population in the European Union are exposed to levels exceeding $55 \mathrm{~dB}(\mathrm{~A}){ }^{8}$

Road traffic noise is suspected of increasing the risk for adiposity. Studies of both cross-sectional and longitudinal designs have rather consistently found transportation noise to increase waist circumference and obesity among adults, whereas results for body mass index (BMI) are less consistent. ${ }^{2-4}$ 9-11 Two recent studies have moreover indicated that traffic noise may affect adiposity in children. ${ }^{12} 13$ Exposure
Key messages

What is already known about this subject?

- Previous studies have indicated that road traffic noise is associated with markers of adiposity among children and elderly populations.

What are the new findings?

- We investigated effects of traffic noise on weight gain in women during and after pregnancy.

- Road traffic noise was associated with an increase in gestational weight gain and postpartum weight retention (PPWR).

- For PPWR, the association seemed confined to overweight and obese women.

How might this impact on policy or clinical practice in the foreseeable future?

- A number of different noise abatement approaches are available.

- The study adds to the existing literature linking traffic noise to risk for adiposity, which is important knowledge to encourage legislation to reduce traffic noise.

to transportation noise is believed harmful through a stress reaction, with activation of the hypothalamic-pituitary-adrenocortical axis, leading to a rise in stress hormones, vascular dysfunction and metabolic abnormalities such as impaired glucose tolerance. ${ }^{14-18}$ Furthermore, exposure to traffic noise during night can disturb sleep, ${ }^{19}$ which has been associated with impaired glucose tolerance, reduced insulin sensitivity and dysregulation of appetiteregulating hormones, ${ }^{17} 1820$ as well as cardiometabolic diseases. ${ }^{20-22}$ Both stress and disturbance of sleep may also lead to an unhealthy lifestyle, and studies have indicated that traffic noise is associated with physical inactivity. ${ }^{23} 24$

Pregnancy is a period where women naturally gain weight. However, a high gestational weight gain (GWG) is a risk factor for maternal postpartum weight retention (PPWR), overweight and obesity, ${ }^{25}$ and thus, pregnancy and the period just after pregnancy may be critical time-windows in relation to development of maternal overweight later in life. Studies have indicated that short sleep duration in the postpartum period is associated with a higher PPWR. ${ }^{26}$ The pregnancy and the postpartum periods are normally characterised by 
marked changes in maternal sleep pattern, with reduced sleep quality and duration, ${ }^{27}$ and, furthermore, a relatively stressful time period for many women. It is, therefore, possible that exposure to traffic noise in these period may negatively affect maternal mental condition and sleep even further by stressing and/or disturbing the sleep of the child (postpartum period) and/ or the mother.

We aimed to study associations between residential exposure to road traffic and railway noise and changes in weight during and after the pregnancy in a national birth cohort with selfreported information on maternal weight before, during and after the pregnancy.

\section{METHODS}

\section{Study population}

The study population consisted of mothers who participated in the Danish National Birth Cohort (DNBC), which is a nationwide survey of 100419 pregnant women. ${ }^{28}$ Briefly, pregnant women were invited to participate in the DNBC at their first pregnancy consultation (gestational week 6-10) in the period from 1996 to 2002. Only women who spoke Danish well and had a permanent address in Denmark were invited. The women participated in two telephone interviews during the pregnancy around gestational weeks 16 and 30 , as well as a postnatal telephone interview 18 months after birth. All the interviews were conducted by trained interviewers and included questions on height, weight, smoking habits, alcohol consumption, breast feeding and parity. The study base of the present study constituted the 90903 DNBC mothers who gave birth to live-born singletons.

\section{Outcomes}

For the present study, we considered two anthropometric outcomes: GWG and PPWR. GWG was estimated as weight gain in gram/week from conception to around gestational week 30 . We assessed this using the following question in the second prenatal maternal interview $(\approx 30$ th gestational week): 'How many kilos did you gain during pregnancy at the present time?', divided by gestational age at the time of the interview. We excluded women who failed to complete the $\approx 30$ weeks interview within an acceptable time frame ( \pm 6 weeks of the median of 31.3 weeks).

PPWR was assessed as weight retention in kilos by subtracting information on maternal weight before pregnancy from the maternal weight reported at the interview around $\approx 18$ months after birth ('What is your present weight?'). Self-reported information on prepregnancy weight was obtained in the first prenatal interview $(\approx$ week 12$)$ : 'How much did you weigh before you got pregnant?'. We excluded women who failed to complete the $\approx 18$ months interview within an acceptable time frame $( \pm 3$ months of the median of 18.8 months).

\section{Exposures}

We collected all residential addresses for all DNBC mothers from conception to $\approx 18$ months after birth (date of the postpartum interview) from the Danish Civil Registration System. For these addresses, we calculated annual levels (for the relevant calendar-years) of road traffic and railway noise using SoundPLAN, which is a calculation programme based on the Nordic prediction method. ${ }^{29}$ Input variables for the noise model include geocode and height (floor) for all addresses together with all Danish buildings polygons. Furthermore, for estimation of road traffic noise the following input variables on traffic were used: annual average daily traffic, distribution of light and heavy vehicles, travel speed and road type for all Danish road links (motorway, express road, road $>6 \mathrm{~m}$, road 3-6 m and other road). For estimation of railway noise, the traffic input variables were annual average daily train lengths, train types and travel speed. We included information on railway noise barriers. We had no information on road surface and road noise barriers. Road traffic and railway noise were calculated as the equivalent continuous A-weighted sound pressure levels at the most exposed facade of the building during day, evening and night, and expressed as $\mathrm{L}_{\text {den }}$.

We calculated time-weighted mean levels of nitrogen dioxide $\left(\mathrm{NO}_{2}\right)$ at all maternal addresses from conception to $\approx 18$ months after birth using the Danish AirGIS dispersion modelling system. ${ }^{30}$ Briefly, AirGIS calculates air pollution each hour at each address as the sum of: (1) air pollution from the nearest street, calculated using information on traffic, geometry of buildings and streets, car fleet emission factors and meteorology; (2) urban background and (3) regional background, estimated from rural monitoring data and national vehicle emissions. AirGIS has been successfully validated. ${ }^{3132} \mathrm{NO}_{2}$ is a well-recognised surrogate for a mix of urban traffic-related air pollutants. ${ }^{33}$

\section{Statistical analyses}

We used linear regression models to calculate associations between exposure to road traffic and railway noise and GWG and PPWR, and log-binomial regression to calculate associations between road traffic noise and risk for retaining $\geq 5 \mathrm{~kg}$ at 18 months post partum. For each person, exposure to traffic noise was calculated as a time-weighted mean from conception to the date of the second gestational interview $(\approx 30$ weeks; GWG analyses) and from conception to the 18 months interview date (PPWR analyses) taking the complete address history (with annual means for all relevant calendar-years for each address) in these periods into account. Data were analysed for noise as continuous variables and as categorical variables $(<50,50-55$, $55-60,60-65$ and $\geq 65 \mathrm{~dB}$ ). We calculated Spearman's rank correlation coefficient to investigate associations between exposures and outcomes.

We investigated the association between road traffic and railway noise and the two outcomes GWG and PPWR in four models: model 1 with no adjustment. Model 2 with adjustment for maternal age at conception $(<25,25-30,30-35$ and $\geq 35$ years), parity (nulliparous, uniparous and multiparous), highest attained education at time of conception (basic (7-12 years), vocational (10-12 years, higher ( $\geq 13$ years)), disposable income at time of conception (household income after taxation and interest per person, adjusted for number of persons in the household; in quintiles), cohabitation (married or living with partner; yes, no); municipality-level income at time of conception (quartiles), as well as mutual adjustment for road traffic noise and railway noise. In addition, analyses of GWG were also adjusted for season at conception (winter (December-February), spring (March-May), summer (June-August), autumn (SeptemberNovember)) and analyses of PPWR were adjusted for breast feeding ( $<6$ months; $\geq 6$ months) obtained from the interview $\approx 18$ months after birth. In model 3 , we further adjusted for two lifestyle covariates from the first prenatal interview $(\approx 12$ th gestational week): smoking (yes, no, no but smoked in early pregnancy) and alcohol consumption (no alcohol, $>0-1$ drink/ week and $>1$ drink/week). In model 4 , we adjusted for the model 3 covariates plus residential exposure to air pollution estimated as $\mathrm{NO}_{2}$ (continuous variables, $\mu \mathrm{g} / \mathrm{m}^{3}$, time-weighted mean from 
conception to $\approx 30$ gestational week for the GWG analyses and from conception to $\approx 18$ months after birth for the PPWR analyses). ${ }^{34}$ These covariates were chosen a priori from review of the literature $e^{35-37}$ and obtained from different sources: maternal age, gestational age, parity, smoking, alcohol consumption and breast feeding from the DNBC interviews, and education, income, and cohabitation from the national registers managed by Statistics Denmark.

We evaluated potential modification of the association between road traffic noise and GWG and PPWR by prepregnancy BMI, railway noise, gestational age at the second pregnancy interview (26-29, 30-33 or 34-37 pregnancy week; for GWG), season at second pregnancy interview (for GWG) and GWG (for PPWR), by introducing interaction terms, and tested using the F-test statistic ( $\mathrm{p}$ values $<0.05$ were considered statistically significant). Road traffic and railway noise were included in the models as continues variables after evaluation with linear spline models with boundaries placed at the nine deciles, which indicated no deviation from linearity. We used SAS V.9.3 (SAS Institute).

\section{RESULTS}

The study base for the GWG analyses included 90903 mothers. From this study base, we excluded 8038 without GWG information (6496 did not participate in the 30-week interview, 1535 reported unknown weight in the 30 weeks and 7 reported implausible GWG); 3464 who failed to complete the 30-week interview within a reasonable time frame ( \pm 6 weeks); 311 with incomplete exposure information and 5025 with incomplete confounder information (3299 because they did not participate in the first prenatal interview), leaving a study population of 74 065 women.

For the PPWR analyses, 64123 women participated in both the interview at the 12th gestational week and 18 month. Of these, we excluded 6834 who were pregnant again at the 18 -month interview, 1706 with unknown prepregnancy or 18 -month postpregnancy weight, 10 with implausible PPWR, 367 with incomplete exposure information, 475 with incomplete confounder information and 2088 women failed to complete the 18-month interview within a reasonable time frame ( \pm 3 months), leaving a study population of 52661 women.

The characteristics of the GWG and PPWR study populations according to exposure to four categories of road traffic noise as well as according to the two outcomes are shown in table 1 and online supplementary table 1 , respectively.

We found prepregnancy BMI, GWG and PPWR to be correlated $(p<0.0001)$, with $\mathrm{R}_{\text {Spearman }}$ of -0.23 for BMI and GWG, -0.19 for BMI and PPWR, and 0.25 for GWG and PPWR. Both outcomes (GWG and PPWR) distributed normally (online supplementary figures 1 and 2), with a median GWG of $312 \mathrm{~g} /$ week (25-75 percentiles (P25-75): 241; 389) and PPWR of $0.0 \mathrm{~kg}$ (P25-75: $-2.0 ; 2.5)$. Road traffic noise in the two examined exposure was correlated $\left(\mathrm{R}_{\text {spearman }}=0.95\right)$. The distributions of road traffic noise in the two time-windows were slightly skewed to the left (online supplementary figure 3 ), and median levels of road traffic noise was $57.4 \mathrm{~dB}(\mathrm{~A})$ (P25-75: 53.1 ; 62.6) for the GWG analyses and $57.5 \mathrm{~dB}(\mathrm{~A})$ (P25-75: $53.2 ; 62.3$ ) for the PPWR analyses. 9.5\% women had a PPWR of $\geq 5 \mathrm{~kg}$. Correlations between road traffic noise and $\mathrm{NO}_{2}$ were moderate, with $R_{\text {Spearman }}$ of 0.46 for the GWG exposure window and 0.50 for PPWR exposure window.

We found that a $10 \mathrm{~dB}(\mathrm{~A})$ increase in mean time-weighted road traffic noise during the pregnancy was associated with a 3.8 g/week higher GWG (95\% CI 2.3 to 5.3) in the fully adjusted model 3 (table 2). In the categorical analysis, we observed highest estimates among the highly exposed. Further adjustment for air pollution resulted in lower GWG estimates: $\beta=1.5 \mathrm{~g} /$ week (95\% CI -0.3 to 3.3) per $10 \mathrm{~dB}(\mathrm{~A})$ after $\mathrm{NO}_{2}$ adjustment. We found no associations between railway noise and GWG, although we observed that in the two highest exposure groups of 60-65 dB(A) and $\geq 65 \mathrm{~dB}(\mathrm{~A})$ the GWG were $2.7 \mathrm{~g} /$ week $(95 \% \mathrm{CI}-4.1$ to 9.5 ) and $4.5 \mathrm{~g} /$ week ( $95 \% \mathrm{CI}-2.7$ to 11.6$)$ higher, respectively, than in the reference group exposed to $<55 \mathrm{~dB}(\mathrm{~A})$ (table 2).

A $10 \mathrm{~dB}(\mathrm{~A})$ increase in mean time-weighted road traffic noise from conception to 18 months post partum was associated with a $0.09 \mathrm{~kg}$ higher PPWR 18 months after birth in the fully adjusted model 3 (table 3 ). There were no associations between railway noise and PPWR. Further adjustment for air pollution in the road traffic noise models, resulted in slightly higher PPWR estimates: $10 \mathrm{~dB}(\mathrm{~A})$ increase in road traffic noise was associated with $0.11 \mathrm{~kg}$ higher PPWR (95\% CI 0.03 to 0.20 ) in models adjusted for $\mathrm{NO}_{2}$.

We observed no modification of the association between road traffic noise and GWG by prepregnancy BMI, gestational age, season or railway noise (table 4). In contrast, we found that for PPWR, the association with road traffic noise seemed confined to women reporting prepregnancy overweight ( $\beta: 0.17 \mathrm{~kg} ; 95 \%$ CI 0.02 to 0.32 per $10 \mathrm{~dB}(\mathrm{~A})$ ) or prepregnancy obesity ( $\beta$ : 0.49 $\mathrm{kg}$; $95 \%$ CI 0.26; 0.73 per $10 \mathrm{~dB}(\mathrm{~A}))$. Similar tendencies were found when investigating whether the association between road traffic noise and PPWR changed according to different GWG. Here, we observed that the association seemed confined to women gaining $\geq 386 \mathrm{~g} /$ week during the pregnancy ( $\beta: 0.18 \mathrm{~kg}$ ), although the interaction was insignificant.

We found no significant association between road traffic noise and risk of retaining $\geq 5 \mathrm{~kg} 18$ months post partum in the whole population, with a risk ratio of 1.03 (95\% CI 0.99 to 1.08) per $10 \mathrm{~dB}(\mathrm{~A})$ (table 5). When investigating this association among women reporting to have a prepregnancy BMI within the normal, overweight or obese range, respectively, we observed some differences.

\section{DISCUSSION}

We found that residential exposure to road traffic noise was associated with slightly higher GWG and PPWR in a Danish cohort, although for GWG adjustment by $\mathrm{NO}_{2}$ lowered the estimates. For PPWR, the association with road traffic noise seemed confined to women reporting prepregnancy BMI within the overweight or obese range, as well as women with a high GWG during the pregnancy. We found suggestions of an association between high levels of railway noise and GWG or PPWR.

The results of the present study are in line with most previous studies, which rather consistently found road traffic noise to be associated with markers of adiposity. ${ }^{2-4} 9-13$ However, our study population of women during and after pregnancy (mean age of 30 years) differs from populations used in previous studies, which focused on either children ${ }^{1213}$ or older populations. ${ }^{2-49-11}$ Pregnancy and postpregnancy are for many women periods associated with stress and disturbance of sleep, ${ }^{27}$ and it is likely that exposure to traffic noise may exacerbate these, by disturbing/ stressing the child, the mother or both, thereby potentially increasing risk for gaining weight. We found that road traffic noise was associated with a slightly higher GWG, and although weight gain during the pregnancy is mainly associated with the growing fetus (including placenta and uterus), a high GWG is a risk factor for overweight in women after the pregnancy. ${ }^{25}$ 
Table 1 Study population characteristics by exposure to road traffic noise

\begin{tabular}{|c|c|c|c|c|c|c|c|c|}
\hline & \multicolumn{4}{|c|}{ Gestational weight gain $(n=74065)$} & \multicolumn{4}{|c|}{ Postpartum weight retention ( $n=52661$ ) } \\
\hline & $\begin{array}{l}<55 \mathrm{~dB}(\mathrm{~A}) \\
(\mathrm{n}=27248)\end{array}$ & $\begin{array}{l}55-60 \mathrm{~dB}(\mathrm{~A}) \\
(\mathrm{n}=18799)\end{array}$ & $\begin{array}{l}60-65 \text { dB(A) } \\
(n=16 \quad 073)\end{array}$ & $\begin{array}{l}\geq 65 \mathrm{~dB}(\mathrm{~A}) \\
(\mathrm{n}=11945)\end{array}$ & $\begin{array}{l}<55 \mathrm{~dB}(\mathrm{~A}) \\
(\mathrm{n}=19011)\end{array}$ & $\begin{array}{l}55-60 \mathrm{~dB}(\mathrm{~A}) \\
(\mathrm{n}=14 \mathrm{ll}\end{array}$ & $\begin{array}{l}60-65 \mathrm{~dB}(\mathrm{~A}) \\
(\mathrm{n}=11791)\end{array}$ & $\begin{array}{l}\geq 65 \mathrm{~dB}(\mathrm{~A}) \\
(\mathrm{n}=7689)\end{array}$ \\
\hline \multicolumn{9}{|l|}{ Age $^{*}$} \\
\hline$<25$ years & 11 & 13 & 14 & 15 & 9 & 11 & 12 & 13 \\
\hline $25-30$ years & 40 & 41 & 44 & 45 & 39 & 41 & 43 & 44 \\
\hline $30-35$ years & 36 & 34 & 32 & 31 & 38 & 35 & 33 & 32 \\
\hline$\geq 35$ years & 12 & 11 & 10 & 9 & 14 & 12 & 12 & 11 \\
\hline \multicolumn{9}{|l|}{ Parity } \\
\hline Nulliparous & 39 & 46 & 51 & 59 & 34 & 41 & 47 & 54 \\
\hline Uniparous & 42 & 38 & 35 & 30 & 44 & 41 & 38 & 34 \\
\hline Multiparous & 19 & 17 & 14 & 11 & 22 & 18 & 15 & 12 \\
\hline \multicolumn{9}{|l|}{ Highest attained education* } \\
\hline Basic (7-12 years) & 13 & 14 & 13 & 14 & 12 & 13 & 13 & 13 \\
\hline Vocational (10-12 years) & 51 & 50 & 49 & 49 & 51 & 50 & 50 & 49 \\
\hline Higher ( $\geq 13$ years) & 36 & 36 & 37 & 37 & 37 & 37 & 38 & 38 \\
\hline \multicolumn{9}{|l|}{ Disposable income (quintiles)* } \\
\hline Q1 (low) & 9 & 11 & 12 & 13 & 8 & 10 & 11 & 12 \\
\hline Q2 & 11 & 12 & 13 & 13 & 11 & 12 & 12 & 13 \\
\hline Q3 & 23 & 22 & 21 & 20 & 23 & 22 & 22 & 21 \\
\hline Q4 & 32 & 29 & 29 & 26 & 33 & 30 & 29 & 28 \\
\hline Q5 (high) & 26 & 26 & 25 & 28 & 25 & 26 & 28 & 26 \\
\hline \multicolumn{9}{|l|}{ Cohabitation (incl. marriage)* } \\
\hline Yes & 90 & 86 & 84 & 82 & 91 & 88 & 86 & 83 \\
\hline No & 10 & 14 & 16 & 18 & 9 & 12 & 14 & 17 \\
\hline \multicolumn{9}{|l|}{ Area-level income* } \\
\hline Q1 (low) & 26 & 24 & 22 & 19 & 26 & 24 & 23 & 20 \\
\hline Q2 & 20 & 21 & 31 & 33 & 20 & 21 & 29 & 32 \\
\hline Q3 & 26 & 26 & 23 & 23 & 26 & 26 & 24 & 23 \\
\hline Q4 (high) & 27 & 29 & 24 & 25 & 28 & 29 & 25 & 26 \\
\hline \multicolumn{9}{|l|}{ Smoking $\dagger$} \\
\hline No & 76 & 74 & 73 & 72 & 77 & 75 & 74 & 72 \\
\hline No, but smoked in early pregnancy & 8 & 9 & 10 & 12 & 8 & 9 & 9 & 11 \\
\hline Yes & 16 & 16 & 17 & 16 & 15 & 16 & 17 & 17 \\
\hline \multicolumn{9}{|l|}{ Alcohol consumptiont } \\
\hline No alcohol & 75 & 76 & 76 & 76 & 74 & 75 & 76 & 75 \\
\hline$>0$ to $\leq 1 \mathrm{drink} /$ week & 13 & 13 & 13 & 13 & 13 & 13 & 13 & 13 \\
\hline$>1$ drink/week & 12 & 11 & 11 & 11 & 12 & 12 & 11 & 12 \\
\hline \multicolumn{9}{|l|}{ Breast feeding $\ddagger$} \\
\hline$<6$ months & - & - & - & - & 39 & 39 & 39 & 38 \\
\hline$\geq 6$ months & - & - & - & - & 61 & 61 & 61 & 62 \\
\hline \multicolumn{9}{|l|}{ Prepregnancy BMI, kg/m² } \\
\hline Normal $(<25)$ & 71 & 72 & 74 & 75 & 71 & 72 & 73 & 75 \\
\hline Overweight (25-30) & 21 & 20 & 19 & 17 & 20 & 20 & 19 & 18 \\
\hline Obese $(\geq 30)$ & 9 & 8 & 8 & 7 & 8 & 8 & 8 & 8 \\
\hline
\end{tabular}

Values are given as percentage.

${ }^{*}$ At conception.

†At first prenatal interview.

fInformation from the fourth interview (app. 18 months after birth).

$\mathrm{BMI}$, body mass index.

We also found an association between road traffic noise and PPWR, which is more likely to reflect an actual increase in body fat, indicating that exposure to road traffic noise during these periods may be associated with development of adiposity.

When comparing our results with the results of the three previous longitudinal studies on road traffic noise and adiposity in adults, some differences were observed: One study found road traffic noise to be associated with a wider waist circumference and risk of central obesity, but no associations with weight gain. ${ }^{3}$ The authors argue that cortisol would be expected to result primarily in central obesity, although they add that effects of noise on sleep may result in general obesity. Similarly, another study found no associations between road traffic and changes in BMI, although they did report an association with risk for obesity, but not with overweight. ${ }^{4}$ Lastly, a study from Denmark found associations between road traffic noise and changes in both weight and waist 
Table 2 Associations between residential exposure to traffic noise and gestational weight gain ( $\mathrm{g} / \mathrm{week}$ )

\begin{tabular}{|c|c|c|c|c|}
\hline $\begin{array}{l}\text { Exposure from conception to } \approx 30 \text { gestational } \\
\text { week }\left(\mathrm{L}_{\text {den }}\right)\end{array}$ & $\mathrm{N}$ & $\begin{array}{l}\text { Model 1* } \\
\boldsymbol{\beta}(95 \% \mathrm{Cl})\end{array}$ & $\begin{array}{l}\text { Model } 2+ \\
\beta(95 \% \mathrm{Cl})\end{array}$ & $\begin{array}{l}\text { Model } 3 \mp \\
\beta(95 \% \mathrm{Cl})\end{array}$ \\
\hline \multicolumn{5}{|l|}{ Road traffic noise } \\
\hline$<55 \mathrm{~dB}(\mathrm{~A})$ & 27244 & 0 (reference) & 0 (reference) & 0 (reference) \\
\hline$(55-60) \mathrm{dB}(\mathrm{A})$ & 18801 & $3.9(1.4$ to 6.3$)$ & $2.2(-0.2$ to 4.6$)$ & $1.7(-0.7$ to 4.1$)$ \\
\hline$(60-65) d B(A)$ & 16073 & 7.8 (5.3 to 10.4$)$ & 5.5 (3.0 to 8.0$)$ & $4.6(2.1$ to 7.1$)$ \\
\hline$\geq 65 \mathrm{~dB}(\mathrm{~A})$ & 11947 & 11.4 (8.6 to 14.2 ) & 7.4 (4.6 to 10.2 ) & 5.9 (3.1 to 8.7$)$ \\
\hline Linear (per $10 \mathrm{~dB}(\mathrm{~A})$ ) & 74065 & 7.0 (5.6 to 8.5$)$ & 4.7 (3.2 to 6.1$)$ & $3.8(2.3$ to 5.3$)$ \\
\hline \multicolumn{5}{|l|}{ Railway noise } \\
\hline$<55 \mathrm{~dB}(\mathrm{~A})$ & 69321 & 0 (reference) & 0 (reference) & 0 (reference) \\
\hline$(55-60) \mathrm{dB}(\mathrm{A})$ & 2092 & $0.8(-4.8$ to 6.5$)$ & $-1.8(-7.5$ to 3.8$)$ & $-2.7(-8.2$ to 2.9$)$ \\
\hline$(60-65) \mathrm{dB}(\mathrm{A})$ & 1404 & $6.9(0.1$ to 13.8$)$ & $4.0(-2.8$ to 10.8$)$ & $2.7(-4.1$ to 9.5$)$ \\
\hline$\geq 65 \mathrm{~dB}(\mathrm{~A})$ & 1248 & 8.4 (1.1 to 15.6$)$ & $5.1(-2.1$ to 12.3$)$ & $4.5(-2.7$ to 11.6$)$ \\
\hline Linear (per $10 \mathrm{~dB}(\mathrm{~A}))$ & 74065 & 0.5 (-1.6 to 2.6$)$ & $0.7(-1.4$ to 2.8$)$ & $0.4(-1.6$ to 2.5$)$ \\
\hline
\end{tabular}

${ }^{*}$ Model 1: unadjusted.

†Model 2: adjusted by age, parity, education, disposable household income, cohabitation, area-level income, season and mutual adjustment for noise from road traffic and railway.

¥Model 3: model 2 plus adjustment for smoking and alcohol consumption.

circumference as well as increased risk of gaining $\geq 5 \mathrm{~kg} .{ }^{9}$ Therefore, although the overall picture when comparing these longitudinal studies is that traffic noise is associated with development of adiposity across different age groups, more epidemiological studies and research into the biological mechanisms behind the observed associations are needed to disentangle whether noise primarily is associated with central obesity, general obesity or both.

Interestingly, we found that the association between road traffic noise and PPWR seemed confined to women who were overweight or obese before pregnancy, as well as an indication of an association between road traffic noise and the risk of gaining $\geq 5 \mathrm{~kg}$ mainly among obese women. This suggests that obese women represent a susceptible group when it comes to the hazardous effects of traffic noise. Part of the explanation might be that obese women generally have poorer sleep than women with a BMI within the normal range, ${ }^{38}$ and therefore, might be more easily disturbed and/or stressed by traffic noise. In support of our findings, a longitudinal study on elderly Danes found similar results, with stronger associations between road traffic noise and increases in weight and waist circumference among people who were obese at baseline compared with people with a BMI below $25 \mathrm{~kg} / \mathrm{m}^{2} .^{9}$ In contrast, a Swedish longitudinal study found no differences in associations between road traffic noise and weight or waist circumference changes according to baseline BMI $\left(<25,25-30\right.$ and $\left.\geq 30 \mathrm{~kg} / \mathrm{m}^{2}\right){ }^{3}$. Therefore, more studies are needed to clarify the role of existing obesity in the noiseadiposity association, as identification of susceptible groups is important from a prevention perspective.

In the analyses of road traffic noise, we found that adjustment by air pollution (estimated as $\mathrm{NO}_{2}$ ) reduced the GWG risk estimates and slightly increased the PPWR risk estimates. Disentangling effects of road traffic noise and air pollution in relation to disease are often challenging, because the two exposures correlates, reflecting that road traffic is an important input variable for both exposure models. Although studies investigating the association between air pollution and adiposity are currently inconclusive with both positive, negative and null findings, ${ }^{34}$ we cannot rule out that for GWG some of the observed association with road traffic noise can be ascribed to air pollution, whereas for PPWR the association with road traffic noise seemed independent from air pollution exposure. In the present study, we

\begin{tabular}{|c|c|c|c|c|}
\hline $\begin{array}{l}\text { Exposure from conception to } 18 \text { months } \\
\text { after birth }\left(\mathrm{L}_{\text {den }}\right)\end{array}$ & $\mathrm{N}$ & $\begin{array}{l}\text { Model 1* } \\
\beta(95 \% \text { Cl) }\end{array}$ & $\begin{array}{l}\text { Model } 2 \dagger \\
\boldsymbol{\beta}(95 \% \mathrm{Cl})\end{array}$ & $\begin{array}{l}\text { Model 3‡ } \\
\beta(95 \% \mathrm{Cl}) \\
\end{array}$ \\
\hline \multicolumn{5}{|l|}{ Road traffic noise } \\
\hline$<55 \mathrm{~dB}(\mathrm{~A})$ & 19011 & 0 (reference) & 0 (reference) & 0 (reference) \\
\hline$(55-60) d B(A)$ & 14170 & $0.18(0.07$ to 0.29$)$ & 0.14 (0.03 to 0.24$)$ & 0.13 (0.03 to 0.24$)$ \\
\hline$(60-65) \mathrm{dB}(\mathrm{A})$ & 11791 & $0.25(0.14$ to 0.36$)$ & $0.18(0.07$ to 0.30$)$ & $0.19(0.07$ to 0.30$)$ \\
\hline$\geq 65 \mathrm{~dB}(\mathrm{~A})$ & 7689 & $0.24(0.11$ to 0.37$)$ & 0.15 (0.01 to 0.28$)$ & 0.14 (0.01 to 0.27$)$ \\
\hline Linear (per $10 \mathrm{~dB}(\mathrm{~A})$ ) & 52661 & 0.16 (0.09 to 0.23$)$ & 0.09 (0.02 to 0.16$)$ & 0.09 (0.02 to 0.16$)$ \\
\hline \multicolumn{5}{|l|}{ Railway noise } \\
\hline$<55 \mathrm{~dB}(\mathrm{~A})$ & 49256 & 0 (reference) & 0 (reference) & 0 (reference) \\
\hline$(55-60) d B(A)$ & 1557 & $-0.16(-0.41$ to 0.09$)$ & -0.21 (0.46 to 0.04$)$ & $-0.22(-0.46$ to 0.03$)$ \\
\hline$(60-65) d B(A)$ & 1027 & $0.12(-0.18$ to 0.43$)$ & $0.07(-0.23$ to 0.38$)$ & $0.08(-0.23$ to 0.38$)$ \\
\hline$\geq 65 \mathrm{~dB}(\mathrm{~A})$ & 821 & $0.30(-0.04$ to 0.64$)$ & 0.25 (-0.09 to 0.60$)$ & $0.26(-0.09$ to 0.60$)$ \\
\hline Linear (per $10 \mathrm{~dB}(\mathrm{~A})$ ) & 52661 & $-0.06(-0.15$ to 0.03$)$ & $-0.04(-0.13$ to 0.05$)$ & $-0.04(-0.12$ to 0.05$)$ \\
\hline
\end{tabular}

*Model 1: unadjusted.

†Model 2: adjusted by age, parity, education, disposable household income, cohabitation, area-level income, breast feeding and mutual adjustment for noise from road traffic and railway.

‡Model 3: model 2 plus adjustment for smoking and alcohol consumption. 
Table 4 Modification of the association between residential road traffic noise and differences gestational weight gain by prepregnancy BMI and in postpartum weight retention (18 months) by prepregnancy BMI, gestational age, season and gestational weight gain

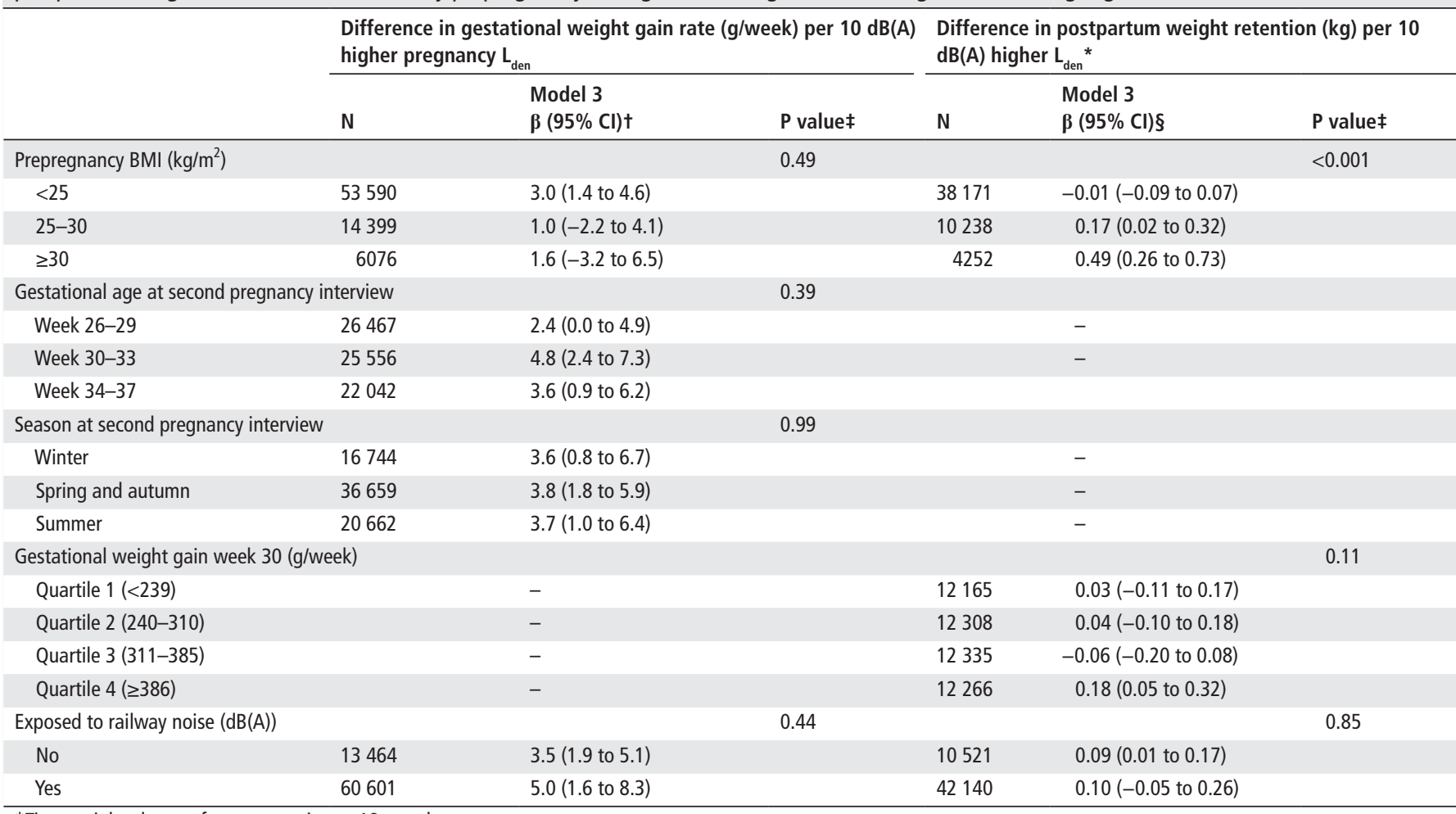

${ }^{*}$ Time-weighted mean from conception to 18 month post partum.

†Adjusted by age, parity, education, disposable household income, cohabitation, area-level income, smoking, alcohol consumption, season and railway noise. $\ddagger \mathrm{P}$ value for interaction.

$\S$ Adjusted by age, parity, education, disposable household income, cohabitation, area-level income, smoking, alcohol consumption, breast feeding and railway noise. BMI, body mass index.

did not have information on exposure to $\mathrm{PM}_{2.5}$, which is a limitation as particles have been shown to be a key air pollutant in relation to development of disease.

We found some suggestions of an association between high levels of railway noise and GWG or PPWR. Three previous longitudinal studies on railway noise and markers of adiposity found no or rather weak indications of associations between railway noise and changes in weight and/or waist circumference. $^{349}$ A potential explanation for the weaker association compared with road traffic noise is that most trains operating in Denmark and other countries are passenger trains, which do usually not run during the night, and may therefore not be associated with disturbance of nocturnal sleep, in the same degree as road traffic noise which continue during night.
Major strengths of our study include the longitudinal design and the large study population, with information on weight and changes in weight over time, together with information on potential confounders from questionnaires and high-quality nationwide registers. ${ }^{3940}$ Furthermore, we had access to residential address histories (before outcome) that enabled us to estimate residential exposure in the relevant time periods taking residential mobility into account.

The main limitation of the present study is that GWG and PPWR were estimated from self-reported information on weight and weight gain, which will inevitably result in misclassification. A validation study based on a Danish cohort of elderly participants ( $>50$ years at enrolment) indicated that participants tended to under-report their weight, and that this underestimation was

Table 5 Association between residential road traffic noise and risk of weight retention of $\geq 5 \mathrm{~kg}$ at 18 months post partum for all and among women with BMI within the normal, overweight and obese range

\begin{tabular}{|c|c|c|c|c|c|c|c|c|}
\hline \multirow{2}{*}{$\begin{array}{l}\mathrm{L}_{\text {den }} \text { road from conception } \\
\text { to } 18 \text { months after birth }\end{array}$} & \multicolumn{2}{|l|}{ All } & \multicolumn{2}{|c|}{ Normal BMI } & \multicolumn{2}{|c|}{ Overweight } & \multicolumn{2}{|l|}{ Obese } \\
\hline & $\mathrm{N}$ cases & $\operatorname{RR}(95 \% \mathrm{Cl})^{*}$ & $N$ cases & $\operatorname{RR}(95 \% \mathrm{Cl})^{*}$ & $\mathrm{~N}$ cases & RR $(95 \% \mathrm{Cl})^{*}$ & $N$ cases & $\operatorname{RR}(95 \% \mathrm{Cl})^{*}$ \\
\hline \multicolumn{9}{|l|}{ Categorical } \\
\hline$<55 \mathrm{~dB}(\mathrm{~A})$ & 1674 & 1 (ref) & 1092 & 1 (ref) & 427 & 1 (ref) & 155 & 1 (ref) \\
\hline $55-60 \mathrm{~dB}(\mathrm{~A})$ & 1368 & 1.05 (0.98 to 1.12$)$ & 881 & 1.03 (0.95 to 1.12 ) & 352 & 1.08 (0.95 to 1.23$)$ & 135 & $1.13(0.91$ to 1.40$)$ \\
\hline $60-65 \mathrm{~dB}(\mathrm{~A})$ & 1177 & 1.06 (0.99 to 1.14$)$ & 785 & 1.05 (0.96 to 1.15$)$ & 286 & 1.11 (0.96 to 1.28$)$ & 106 & 1.09 (0.86 to 1.37$)$ \\
\hline$\geq 65 \mathrm{~dB}(\mathrm{~A})$ & 770 & 1.03 (0.95 to 1.12$)$ & 541 & 1.06 (0.96 to 1.17$)$ & 156 & 0.94 (0.79 to 1.12$)$ & 73 & 1.16 (0.89 to 1.51$)$ \\
\hline Linear, per $10 \mathrm{~dB}(\mathrm{~A})$ & 4989 & 1.03 (0.98 to 1.07 ) & 3299 & 1.04 (0.99 to 1.10$)$ & 1221 & 0.99 (0.90 to 1.08$)$ & 469 & 1.08 (0.94 to 1.25$)$ \\
\hline
\end{tabular}

\footnotetext{
*Adjusted by age, parity, education, disposable household income, cohabitation, area-level income, smoking, alcohol consumption, breast feeding and railway noise.
} BMI, body mass index. 
highest among participants with high $\mathrm{BMI},{ }^{41}$ which may lead to bias of the results. However, the focus of the present study was gain in weight, which might be less affected by such biassed misclassification compared with a cross-sectional design, at least if the under-reporting of weight is systematic over time for each woman. Also, pregnancy and the period just after pregnancy are periods with increased focus on weight, as the women in these periods attend a number of healthcare visits where their weight are measured, which probably results in a more precis self-reporting of weight. Furthermore, reporting of BMI might be associated with noise exposure, through an impact of socioeconomic status (SES) on both, but we observe only minor differences in SES according to noise suggesting that this is not a major problem.

A limitation in the GWG assessment is that the time of the second pregnancy interview varied from gestational week 26 to 37 . The weight gain rate is higher during second and third trimester compared with first trimester, and therefore, the GWG estimated in our study will tend to be higher for women interviewed late compared with early. However, we found that gestational age at the second interview did not modify the noise-GWG association, indicating weak or no influences on the estimates. In addition, environmental exposures such as air pollution have been found to have different impacts in different trimesters. However, as noise estimates in the present study were based on annual estimates, trimester-specific analyses were not possible.

Other limitations include lack of information on various individual factors that might influence the personal exposure, for example, information on time at home and window opening habits. We observed that adjustment by SES and lifestyle confounders resulted in a marked decrease in estimate size, suggesting that residual confounding may be an issue. However, including smoking and alcohol as potential confounders may result in overadjustment, as they have been suggested to be mediators rather than confounders. ${ }^{42}$ We did not have information of ethnicity, but inclusion of only women who spoke Danish well enough to complete the long interviews virtually excluded all other ethnicities than Danish through generations. Lastly, the results cannot be readily generalised to the whole population, as only $30 \%$ of the eligible pregnant women in Denmark participated in the cohort, and they have been indicated to have higher SES than non-participants. ${ }^{43}$

In conclusion, we found that exposure to road traffic noise and possibly high levels of railway noise was associated with slightly higher GWG and PPWR, although for GWG some of the observed association may possibly be ascribed to air pollution. The association between road traffic noise and PPWR seemed confined to women who were overweight or obese before pregnancy, suggesting that these women constitute a susceptible population that may benefit from noise preventive initiatives.

Contributors MS, OR-N and TIAS conceived the present study. MK geocoded addresses and estimated air pollution. MS conducted the statistical analyses and wrote the first manuscript draft. All authors commented and contributed to the final manuscript.

Funding The Danish National Birth Cohort was established with a significant grant from the Danish National Research Foundation. Additional support was obtained from the Danish Regional Committees, the Pharmacy Foundation, the Egmont Foundation, the March of Dimes Birth Defects Foundation, the Health Foundation and other minor grants.

Competing interests None declared.

Patient consent for publication Not required.

Ethics approval The Danish National Birth Cohort has been approved by the Danish Scientific Ethics Committee.
Provenance and peer review Not commissioned; externally peer reviewed. Data availability statement No data are available.

\section{ORCID iD}

Mette Sørensen http://orcid.org/0000-0002-7302-4789

\section{REFERENCES}

1 Hänninen $\mathrm{O}$, Knol $\mathrm{AB}$, Jantunen $\mathrm{M}$, et al. Environmental burden of disease in Europe: assessing nine risk factors in six countries. Environ Health Perspect 2014;122:439-46.

2 Christensen JS, Raaschou-Nielsen 0, Tjønneland A, et al. Road traffic and Railway noise exposures and adiposity in adults: a cross-sectional analysis of the Danish diet, cancer, and health cohort. Environ Health Perspect 2016;124:329-35.

3 Pyko A, Eriksson C, Lind T, et al. Long-term exposure to transportation noise in relation to development of Obesity-a cohort study. Environ Health Perspect 2017; 125:117005.

4 Foraster M, Eze IC, Vienneau D, et al. Long-term exposure to transportation noise and its association with adiposity markers and development of obesity. Environ Int 2018:121:879-89.

5 Sørensen M, Andersen ZJ, Nordsborg RB, et al. Long-term exposure to road traffic noise and incident diabetes: a cohort study. Environ Health Perspect 2013;121:217-22.

6 Clark C, Sbihi H, Tamburic L, et al. Association of long-term exposure to transportation noise and traffic-related air pollution with the incidence of diabetes: a prospective cohort study. Environ Health Perspect 2017;125:087025.

7 World Health Organization. Environmental noise guidelines for the European region. WHO Regional Office for Europe, 2018.

8 European Environment Agency. Report: noise in Europe 2014. Publications Office of the European Union, 2014.

9 Christensen JS, Raaschou-Nielsen 0, Tjønneland A, et al. Long-term exposure to residential traffic noise and changes in body weight and waist circumference: a cohort study. Environ Res 2015;143:154-61.

10 Oftedal B, Krog NH, Pyko A, et al. Road traffic noise and markers of obesity - a population-based study. Environ Res 2015;138:144-53.

11 Pyko A, Eriksson C, Oftedal B, et al. Exposure to traffic noise and markers of obesity. Occup Environ Med 2015:72:594-601.

12 Christensen JS, Hjortebjerg D, Raaschou-Nielsen 0, et al. Pregnancy and childhood exposure to residential traffic noise and overweight at 7 years of age. Environ Int 2016;94:170-6.

13 Weyde KV, Krog NH, Oftedal B, et al. A longitudinal study of road traffic noise and body mass index trajectories from birth to 8 years. Epidemiology 2018;29:729-38.

14 Münzel T, Schmidt FP, Steven S, et al. Environmental noise and the cardiovascular system. J Am Coll Cardiol 2018;71:688-97.

15 Schmidt F, Kolle K, Kreuder K, et al. Nighttime aircraft noise impairs endothelial function and increases blood pressure in patients with or at high risk for coronary artery disease. Clin Res Cardiol 2015;104:23-30.

16 Münzel T, Daiber A, Steven $\mathrm{S}$, et al. Effects of noise on vascular function, oxidative stress, and inflammation: mechanistic insight from studies in mice. Eur Heart J 2017;38:2838-49.

17 Thiesse L, Rudzik F, Spiegel K, et al. Adverse impact of nocturnal transportation noise on glucose regulation in healthy young adults: effect of different noise scenarios. Environ Int 2018;121:1011-23.

18 Eze I, Imboden M, Foraster M, et al. Exposure to night-time traffic noise, MelatoninRegulating gene variants and change in glycemia in adults. Int J Environ Res Public Health 2017;14:1492.

19 Basner M, McGuire S. Who environmental noise guidelines for the European region: a systematic review on environmental noise and effects on sleep. Int J Environ Res Public Health 2018;15:519.

20 McHill AW, Wright KP. Role of sleep and circadian disruption on energy expenditure and in metabolic predisposition to human obesity and metabolic disease. Obes Rev 2017; 18:15-24.

21 Cappuccio FP, D'Elia L, Strazzullo P, et al. Quantity and quality of sleep and incidence of type 2 diabetes: a systematic review and meta-analysis. Diabetes Care 2010:33:414-20.

22 St-Onge M-P, Grandner MA, Brown D, et al. Sleep duration and quality: impact on lifestyle behaviors and cardiometabolic health: a scientific statement from the American heart association. Circulation 2016;134:e367-86.

23 Roswall N, Ammitzbø\|ll G, Christensen JS, et al. Residential exposure to traffic noise and leisure-time sports - a population-based study. Int J Hyg Environ Health 2017;220:1006-13.

24 Foraster M, Eze IC, Vienneau D, et al. Long-term transportation noise annoyance is associated with subsequent lower levels of physical activity. Environ Int 2016:91:341-9.

25 Rong K, Yu K, Han X, et al. Pre-pregnancy BMI, gestational weight gain and postpartum weight retention: a meta-analysis of observational studies. Public Health Nutr 2015;18:2172-82. 
26 Xiao RS, Kroll-Desrosiers AR, Goldberg RJ, et al. The impact of sleep, stress, and depression on postpartum weight retention: a systematic review. J Psychosom Res $2014 ; 77: 351-8$

27 Sivertsen B, Hysing M, Dørheim SK, et al. Trajectories of maternal sleep problems before and after childbirth: a longitudinal population-based study. BMC Pregnancy Childbirth 2015;15:129.

28 Olsen J, Melbye M, Olsen SF, et al. The Danish National Birth Cohort--its background, structure and aim. Scand J Public Health 2001;29:300-7.

29 Bendtsen $\mathrm{H}$. The Nordic prediction method for road traffic noise. Sci Total Environ 1999:235:331-8.

30 Jensen SS, Berkowicz R, Sten Hansen H, et al. A Danish decision-support GIS tool for management of urban air quality and human exposures. Transp Res D Transp Environ 2001;6:229-41.

31 Khan J, Kakosimos K, Raaschou-Nielsen 0, et al. Development and performance evaluation of new AirGIS - a GIS based air pollution and human exposure modelling system. Atmos Environ 2019;198:102-21.

32 Ketzel M, Berkowicz R, Hvidberg M, et al. Evaluation of AirGIS: a GIS-based air pollution and human exposure modelling system. Int J Environ Pollution 2011:47:226-38.

33 Levy I, Mihele C, Lu G, et al. Evaluating multipollutant exposure and urban air quality: pollutant interrelationships, neighborhood variability, and nitrogen dioxide as a proxy pollutant. Environ Health Perspect 2014;122:65-72.
34 An R, Ji M, Yan H, et al. Impact of ambient air pollution on obesity: a systematic review. Int J Obes 2018;42:1112-26.

35 O'Brien EC, Alberdi G, McAuliffe FM. The influence of socioeconomic status on gestational weight gain: a systematic review. J Public Health 2018;40:41-55.

36 Aubin $\mathrm{H}-\mathrm{J}$, Farley $\mathrm{A}$, Lycett $\mathrm{D}$, et al. Weight gain in smokers after quitting cigarettes: meta-analysis. BMJ 2012;345:e4439.

$37 \mathrm{He}$ X, Zhu M, Hu C, et al. Breast-feeding and postpartum weight retention: a systematic review and meta-analysis. Public Health Nutr 2015;18:3308-16.

38 Hargens Tet al. Association between sleep disorders, obesity, and exercise: a review. Nat Sci Sleep 2013;5:27-35.

39 Jensen VM, Rasmussen AW, Registers DE. Danish education registers. Scand J Public Health 2011;39:91-4.

40 Baadsgaard M, Quitzau J. Danish registers on personal income and transfer payments. Scand J Public Health 2011;39:103-5.

41 Bigaard J, Spanggaard I, Thomsen BL, et al. Self-reported and technicianmeasured waist circumferences differ in middle-aged men and women. J Nutr 2005; 135:2263-70.

42 Roswall N, Christensen JS, Bidstrup PE, et al. Associations between residential traffic noise exposure and smoking habits and alcohol consumption-A population-based study. Environ Pollut 2018;236:983-91.

43 Jacobsen TN, Nohr EA, Frydenberg M. Selection by socioeconomic factors into the Danish National Birth Cohort. Eur J Epidemiol 2010;25:349-55. 